\title{
ISLAMIC SOCIAL REPORTING (ISR) PADA PERBANKAN SYARIAH DI INDONESIA
}

\author{
Lulu Amalia Nusron'; Rani Eka Diansari² \\ Fakultas Bisnis Universitas PGRI Yogyakarta \\ Jl. IKIP PGRI I Sonosewu No.117, Sonosewu, Ngestiharjo, Kasihan, Bantul \\ E-mail: lulu.amalia@upy.ac.id \\ diterima: 24/11/2020; direvisi: 19/1/2021; diterbitkan: 26/3/2021
}

\begin{abstract}
This research aims to determine the profitability, liquidity, company size, leverage, and Islamic governance of Indonesian Islamic Bank reporting on Islamic society. The study period is from 2016 to 2019 . This study uses quantitative methods. The population is all Islamic banking operations in Indonesia registered with OJK from 2016 to 2019. The sample was determined through purposeful sampling techniques, therefore, 32 financial reports from 8 BUS. The analysis uses multiple linear regression. The results concluded: (1) Profitability has no influence on Islamic social reports. (2) Mobility has no influence on Islamic social reports. (3) The size of the company has no influence on Islamic social reports. (4) Leverage influences Islamic social reports. (5) The age of the company has no influence on Islamic social reports. (6) The score of Islamic governance has no effect on Islamic social reports
\end{abstract}

Keywords: Profitability, Liquidity, Company Size, Leverage, Company Age, Islamic Governance Score, Islamic Social Reporting (ISR) Disclosure.

\section{PENDAHULUAN}

Perbankan syariah yang semakin berkembang bersamaan dengan ekonomi negara akan menjadi sorotan oleh masyarakat. Pertanggungjawaban sosial perusahaan berbasis syariah atau Islamic Social Responsibility (ISR) menjadi salah satunya karena berhubungan langsung dengan lingkungan perusahaan dan masyarakat luas (Aini, Susilowati, Indarti, \& Age, 2017).

Konsep ISR merupakan pengembangan dari praktik Corporate Social Responsibility (CSR) yang telah diwajibkan oleh pemerintah untuk semua sektor usaha berbadan hukum Perseroan Terbatas dengan diterbitkannya "Undang-Undang No. 40 Tahun 2007 tentang Perseroan Terbatas dan Peraturan Pemerintah No. 47 Tahun 2012 tentang Tanggung Jawab Sosial dan Lingkungan Perseroan Terbatas". Namun, pemerintah belum menerbitkan Undang-Undang resmi atau pedoman baku tentang pelaporan tanggung jawab sosial untuk perusahaan berbasis syariah sehingga hasil akhir laporan setiap masing-masing perusahaan akan berbeda karena masih bersifat sukarela atau tidak wajib.

Patokan pelaporan yang dikembangkan oleh AAOIFI sebagai acuan pengukuran dalam pelaksanaan CSR sesuai perspektif Islam. Acuan pengukuran tersebut menjadi indikator ISR dan telah dikembangkan menjadi 6 tema, diantara lain "pendanaan dan Investasi, produk dan jasa, karyawan, masyarakat, lingkungan hidup, dan tata kelola perusahaan" (Sunarsih \& Ferdiyansyah, 2017).

Penelitian yang dilakukan (Herawati, Rawi, \& Destiana, 2019) dan (Lestari, 2016) menyatakan bahwa "profitabilitas tidak berpengaruh terhadap pengungkapan Islamic Social Reporting". Namun penelitian lain yaitu (Affandi \& Nursita, 2019), (Widiyanti \& Hasanah, 2017), dan (Eksandy \& Hakim, 2018) menyatakan bahwa "profitabilitas berpengaruh terhadap pengungkapan Islamic Social Reporting".

Penelitian terdahulu yang dilakukan (Yentisna \& Alvian, 2019), 
(Aziz, Roekhudin, \& Andayani, 2019), dan (Dewi \& Putri, 2018) menyatakan bahwa "likuiditas tidak berpengaruh terhadap pengungkapan Islamic Social Reporting". Namun, penelitian lain yaitu (Affandi \& Nursita, 2019), (Widiyanti \& Hasanah, 2017), dan (Maulina \& Iqramuddin, 2019) memiliki pengaruh pada Islamic Social Reporting.

Penelitian terkait ukuran perusahaan yang dilakukan (Hidayah \& Wulandari, 2017) dan (Eksandy \& Hakim, 2018) menyatakan bahwa "ukuran berpengaruh terhadap pengungkapan Islamic Social Reporting. Namun, penelitian lain yaitu (Affandi \& Nursita, 2019), (Lestari, 2016) menyatakan tidak berpengaruh terhadap pengungkapan Islamic Social Reporting".

Penelitian terkait leverage perusahaan yang dilakukan (Maulina \& Iqramuddin, 2019) menyatakan bahwa "leverage berpengaruh terhadap pengungkapan Islamic Social Reporting. Namun penelitian lain, (Affandi \& Nursita, 2019), (Eksandy \& Hakim, 2018), (Sulistyawati \& Yuliani, 2017), (Lestari, 2016) menyatakan tidak berpengaruh terhadap pengungkapan Islamic Social Reporting".

Penelitian terkait umur perusahaan yang dilakukan Hidayah dan Wulandari (2017) menyatakan bahwa "umur perusahaan mempunyai arah pengaruh yang positif dan signifikan terhadap pengungkapan ISR". Penelitian dari Nuraeni dan Rini (2019) menghasilkan "Islamic Governance Score berpengaruh terhadap pengungkapan Islamic Social Reporting".

Berdasarkan berbagai macam hasil penelitian yang telah dilakukan dan bersifat inkonsisten, maka peneliti akan melakukan penelitian tentang adakah pengaruh profitabilitas, likuiditas, ukuran perusahaan, leverage dan islamic governance terhadap islamic social reporting pada perbankan syariah di Indonesia.

\section{TINJAUAN PUSTAKA}

CSR yakni

komitmen

berkelanjutan pelaku bisnis atau perusahaan agar terlibat dalam pembangunan ekonomi dan menaikkan kualitas hidup pekerja beserta keluarga, komunitas, serta masyarakat umum (Taufik, Widianti, \& Rafiqoh, 2015). Pandangan bank konvensional masih meyakini bahwa pelaporan CSR perusahaan hanya berfokus pada dimensi hubungan horizontal yaitu materi dan hubungan antar manusia. Sedangkan untuk perbankan syariah harus menitikberatkan di aspek religius dalam pelaporan tanggung jawab sosialnya yang berdasar ketentuan Islam (Astuti, 2019).

"ISR menjadi aturan baku pelaporan kinerja sosial seluruh perseroan dengan basis syariat Islam. ISR mempunyai dua tujuan penting, yakni sebagai wujud akuntabilitas pada Allah SWT serta masyarakat dan membantu peningkatan transparansian aktivitas bisnis melalui pengungkapan informasi yang relevan guna memenuhi kebutuhan spiritual para pengambil keputusan muslim (Citravury, Mulyati, \& Icih, 2019).

Profitabilitas yaitu potensi keuntungan yang diperoleh bank dari kegiatan bisnisnya (Mokoginta, Karamoy, \& Lambey, 2018). Bertambah banyaknya nilai profitabilitas, menjadikan perusahaan berpeluang tinggi untuk tumbuh. Bertambah tinggi laba perusahaan, menjadikannya bisa menanggung lebih tingginya biaya guna menyusun pengungkapan laporan sosial (Taufik et al., 2015).

Likuiditas yang tinggi menyebabkan suatu entitas berkeinginan memperluas cakupan Islamic Social Reporting (Hasanah, Widiyanti, \& Sudarno, 2017). Rasio likuiditas dapat sebagai pertanda untuk perusahaan lain 
bahwa perusahaan dalam kondisi aman dengan diungkapkan melalui laporan tanggung jawab sosial perusahaan (Aziz et al., 2019).

Perusahaan besar cenderung banyak permintaan untuk keterbukaan informasi yang lebih tinggi dibandingkan perusahaan kecil. Jumlah terbesar stakeholders di bank syariah merupakan umat islam, Stakeholder memerlukan pengungkapan informasi secara menyeluruh tentang kegiatan perusahaan dimana stakeholder melakukan investasi (Ramadhani et al., 2016).

Tingkat leverage berfungsi untuk menentukan kemampuan entitas agar dapat memenuhi semua kewajiban entitas kepada pihak ketiga. Entitas wajib menjelaskan kepada pemangku kepentingan untuk melunasi pinjaman dan imbasnya terhadap aktivitas perusahaan (Ramadhani et al., 2016). Semakin tinggi leverage maka akibat yang ditanggung bank semakin besar apabila gagal mengelola utangnya dengan baik.

Nuraeni dan Rini (2019) menyatakan perusahaan yang sudah berdiri lama biasanya lebih suka membagikan informasi kepada masyakat. Perusahaan dengan umur yang lebih panjang biasanya lebih mampu bertahan dalam menghadapi lika liku bisnis dan menjaga perusahaan agar lebih konsisten. Oleh karena itu, dalam penelitian ini kita bisa menguji umur perusahaan dengan melihat seberapa besar kemampuan perusahaan dalam mempertahankan keberlangsungan hidup.

Karakteristik islamic governance bisa diukur dari ada atau tidak adanya anggota dewan pengawas syariah, berapa banyak orang yang menjabat sebagai dewan pengawas syariah, pendidikan yang telah ditempuh dewan pengawas syariah, track record dalam bekerja, serta cross membership (Farook dan Lanis, 2005). Dewan pengawas syariah memiliki kemampuan membandingkan beberapa pelaporan tanggung jawab sosial perusahaan syariah

\section{METODE PENELITIAN}

"Penelitian ini menggunakan sumber data sekunder yang didapat dari laporan keuangan tahunan atau annual report perusahaan. Populasi penelitian yaitu Bank Umum Syariah (BUS) yang teregistrasi di OJK periode 2016-2019. Teknik pengambilan sampel menggunakan metode purposive sampling dengan menetapkan kriteria sebagai berikut: 1) Bank Umum Syariah (BUS) yang teregistrasi di Otoritas Jasa Keuangan (OJK) pada tahun 2016-2019; 2) BUS yang menerbitkan annual report periode tahun 2016-2019; 3) BUS yang tidak mengalami kerugian selama tahun 2016-2019”. Peneliti mendapatkan 8 BUS diantara lain Bank Muamalat Indonesia, BRI Syariah, BNI Syariah, Bank Mandiri Syariah, Bank Mega Syariah, Bank Bukopin Syariah, BCA Syariah, dan BTPN Syariah.

$\begin{array}{cccr}\text { Variabel ISR diukur melalui } & \text { doto } \\ \text { metode dummy dengan } & \text { total }\end{array}$ pengungkapan yang ditetapkan sebanyak 48 item. "Variabel profitabilitas diukur menggunakan rasio ROA (return of asset) dimana laba bersih dibagi total aset" (Affandi \& Nursita, 2019). "Variabel likuiditas diukur menggunakan rasio Financing to Deposit Ratio (FDR) yaitu total pembiayaan yang diberikan dibagi total dana pihak ketiga" (Nuraeni \& Rini, 2019). Variabel ukuran perusahaan diukur berdasarkan jumlah aset perusahaan (Wahyuni, 2018). "Variabel umur perusahaan dapat dihitung dari sejak berdirinya perusahaan sampai akhir tahun diterbitkannya annual report" (Nuraeni dan Rini, 2019). "Variabel leverage diukur dengan menggunakan rasio Debt to Equity (DER) yaitu dengan membandingkan total kewajiban dan total ekuitas" (Affandi \& Nursita, 2019). 
Jurnal Ilmiah Ekonomi dan Bísnis

Vol. 18. No.1,Maret $2021: 65-73$

EISSN : $2442-9813$

ISSN : $1829-9822$

Variabel Islamic Governance Score (IGS) diukur melalui komposisi dewan pengawas syariah yang diukur dari: "1) Shariah Supervisory Board (SSB) yaitu jika ada diberi nilai 1 , jika tidak maka 0 ; 2) Jumlah DPS yaitu sama dengan atau lebih dari tiga maka diberi nilai 1 , jika tidak maka 0; 3) Cross membership yaitu jika iya maka diberi nilai 1 , jika tidak maka 0; 4) Latar belakang pendidikan yaitu jika DPS mempunyai pendidikan S2, S3, dan lainnya maka diberi nilai 1 , jika tidak maka $0 ; 5$ ) Pengalaman atau reputasi yaitu jika DPS mempunyai pengalaman di lembaga atau institusi lain maka diberi nilai 1, jika tidak maka 0" (Taufik et.al., 2015).

"Penelitian ini menggunakan software SPSS. Untuk analisis data menggunakan uji asumsi klasik yaitu uji normalitas, uji multikolinearitas, uji heteroskedastisitas, dan uji autokorelasi. Untuk pengujian hipotesis menggunakan uji regresi linear berganda, uji $\mathrm{F}$, uji $\mathrm{T}$, dan koefisien determinasi (R2)".

Adapun hipotesis dalam penelitian ini adalah sebagai berikut:

\begin{tabular}{|c|c|c|}
\hline H1 & : & $\begin{array}{l}\text { Profitabilitas Berpengaruh Terhadap } \\
\text { Islamic Social Reporting (ISR) }\end{array}$ \\
\hline $\mathrm{H} 2$ & : & $\begin{array}{l}\text { Likuiditas Berpengaruh Terhadap } \\
\text { Islamic Social Reporting (ISR) }\end{array}$ \\
\hline H3 & : & $\begin{array}{l}\text { Ukuran Perusahaan Berpengaruh } \\
\text { Terhadap Islamic Social Reporting } \\
\text { (ISR) }\end{array}$ \\
\hline H4 & : & $\begin{array}{l}\text { Leverage Berpengaruh Terhadap } \\
\text { Islamic Social Reporting (ISR)" }\end{array}$ \\
\hline H5 & : & $\begin{array}{l}\text { Umur Perusahaan Berpengaruh } \\
\text { Terhadap Islamic Sosial Reporting } \\
\text { (ISR) }\end{array}$ \\
\hline H6 & : & $\begin{array}{l}\text { Islamic Social Reporting (ISR) } \\
\text { Berpengaruh Terhadap Islamic Sosial } \\
\text { Reporting (ISR)". }\end{array}$ \\
\hline
\end{tabular}

HASIL DAN PEMBAHASAN

\begin{tabular}{|l|c|c|c|c|c|}
\hline & $\mathrm{N}$ & Min & Max & Mean & Std. Deviation \\
\hline Profitabilitas & 32 & 0.02 & 13.60 & 2.1922 & 3.69592 \\
\hline Likuiditas & 32 & 52.56 & 95.60 & 81.6216 & 11.21395 \\
\hline Size & 32 & 15.42 & 24.77 & 18.0934 & 2.76418 \\
\hline Leverage & 32 & 0.38 & 3.50 & 1.6112 & 0.86523 \\
\hline Age & 32 & 2.00 & 27.00 & 11.8750 & 6.83327 \\
\hline IGS & 32 & 3.00 & 4.00 & 3.3125 & 0.47093 \\
\hline ISR & 32 & 0.73 & 0.94 & 0.8359 & 0.06440 \\
\hline Valid N (listwise) & 32 & & & & \\
\hline
\end{tabular}

Peneliti mendapatkan sampel sejumlah 32 dari 8 BUS selama 4 tahun periode. Sampel tersebut dianalisis berdasarkan statistik deskriptif yang dijelaskan pada tabel 1 dengan nilai minimum pada profitabilitas 0.02 nilai maximum 13.60, mean 2.1922, dan memiliki standar deviasi sebesar 3.69592. Variabel likuiditas memiliki nilai minimum 52.56, nilai maximum 95.60, mean 81.6216 dan memiliki standar deviasi 11.21395. Variabel ukuran perusahan nilai minimum sebesar 15.42, nilai maximum 24.77, memiliki mean 18.0934 dan standar deviasi 2.76418. Variabel Leverage nilai minimum sebesar 0.38 , nilai maximum 3.50, mean 1.6112, dan memiliki standar deviasi 2.2851. Variabel age atau umur perusahaan memiliki nilai minimum 2.00, maximum 27.00, dan mean 11.8750. Variabel IGS memiliki nilai minimum 3.00, maximum 4.00, dan mean 3.3125. Variabel dependen yaitu ISR memiliki nilai minimum sebesar 0.73 , nilai maximum 0.94 , mean 0.8359 , dan memiliki standar deviasi 0.06440 . Nilai $\mathrm{N}$ bermakna keseluruhan sampel pada penelitian yakni memanfaatkan laporan tahunan dengan periode empat tahun di 8 bank umum syariah sehingga didapatkan 32 sampel.

Gambar 1. Hasil Uji Normalitas

Normal P-P Plot of Regression Standardized Residual

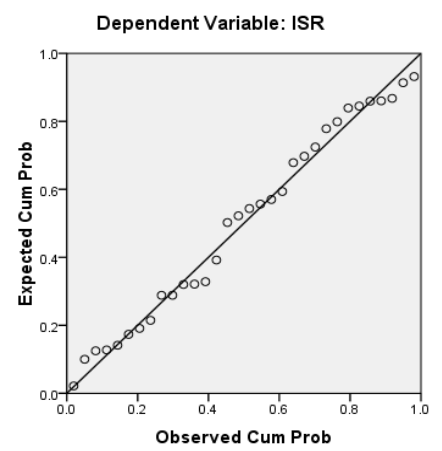

Hasil uji normalitas yang menggunakan Normal Probability P-Plot ditunjukkan pada Gambar 1 yakni grafik memberikan distribusi normal dikarenakan terlihat grafik tersebar berdekatan 
disepanjang serta mengikutii garis diagonal, sehingga terdistribusi normal dan layak untuk dipakai dalam penelitian.

Tabel 2. Hasil Uji Multikoliniearitas

\begin{tabular}{|c|c|c|}
\hline \multirow[t]{2}{*}{ Model } & \multicolumn{2}{|c|}{ Collinearity Statistics } \\
\hline & Tolerance & VIF \\
\hline Profitabilitas & 0.556 & 1.799 \\
\hline Likuiditas & 0.544 & 1.839 \\
\hline Size & 0.521 & 1.918 \\
\hline Leverage & 0.599 & 1.671 \\
\hline Age & 0.285 & 3.514 \\
\hline IGS & 0.521 & 1.921 \\
\hline
\end{tabular}

Uji mulikolinearitas menggunakan metode VIF untuk melihat korelasi antar variabel bebas nya. Tabel 2 memperlihatkan hasil uji yang tidak mengalami masalah multikolinieritas karena VIF tiap variabel berada pada angka $<10$ dan tolerance di bawah 1 .

Gambar 2. Hasil Uji Heteroskedastisitas

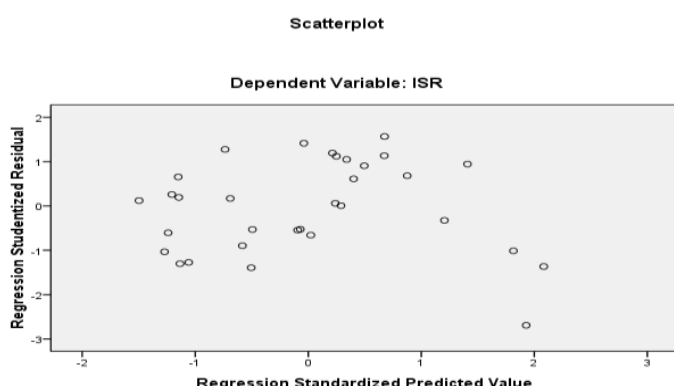

Uji heterokedastisitas berfungsi guna memperoleh gambaran apakah dalam model muncul beda variance residual satu observasi menuju observasi lainnya. Hasilnya ditampilkan pada Gambar 2 dengan menggunakan grafik scatterplot yang memperlihatkan sebaran polanya acak, serta tidak teratur atau jelas, sehingga kesimpulannya tidak muncul gejala heteroskedatisitas.

Tabel 3. Hasil Uji Autokorelasi

\begin{tabular}{lc}
\hline Model & Durbin-Watson \\
\hline 1 & 1.086 \\
\hline
\end{tabular}

Tabel 3 menunjukkan hasil uji autokorelasi dengan menggunakan Durbin Watson dimana nilai DW sebesar 1.086 bermakna tidak terjadi autokorelasi karena nilai DW ada ditengah antara -2 dan +2 .

Tabel 4. Hasil Uji F

\begin{tabular}{ccc}
\hline Model & F & Sig \\
\hline $\begin{array}{l}\text { 1 Regression } \\
\text { Residual }\end{array}$ & 5.000 & $0.002^{\mathrm{a}}$ \\
Total & & \\
\hline
\end{tabular}

Tabel 4 menunjukkan hasil uji $\mathrm{F}$ sebesar 5.000 dengan tingkat signifikansi yang diperoleh sebesar $0.002<0.05$ sehingga dapat disimpulkan jika profitabilitas, likuiditas, ukuran perusahaan, leverage, umur perusahaan, dan islamic governance score memiliki pengaruh secara bersamaan pada islamic social reporting.

\begin{tabular}{lll}
\multicolumn{2}{l}{ Tabel 5. Hasil Uji T } \\
\hline Model & T & Sig. \\
\hline 1 (Constant) & 3.866 & 0.001 \\
Profitabilitas & 0.415 & 0.682 \\
Likuiditas & 1.967 & 0.060 \\
Size & 0.827 & 0.416 \\
Leverage & 4.725 & 0.000 \\
Age & -0.222 & 0.826 \\
IGS & 0.680 & 0.503 \\
\hline
\end{tabular}

"Uji parsial atau uji t-test dilakukan untuk mengetahui seberapa besar pengaruh signifikan dari variabel independen secara individu terhadap variabel dependen. Tabel 5 menunjukkan variabel profitabilitas, likuiditas, ukuran perusahaan, umur perusahaan, dan islamic governance score tidak memiliki pengaruh pada islamic social reporting karena nilai signifikansi nya lebih besar dari 0.05 sehingga $\mathrm{H} 1, \mathrm{H} 2$, H3, H5, dan H6 tidak terdukung atau ditolak. Sedangkan variabel leverage merupakan satu-satunya variabel yang memiliki pengaruh terhadap ISR karena nilai $\mathrm{t}$ hitung sebesar 4.725 dengan sig $=0.000<0.05$ sehingga $\mathrm{H} 4$ terdukung atau diterima". 
Jurnal Ilmiah Ekonomi dan Bisnis

Vol. 18. No.1,Maret $2021: 65-73$

EISSN : $2442-9813$

ISSN : $1829-9822$

Tabel 6. Hasil Uji Koefisien Determinasi

\begin{tabular}{llll}
\hline Model & \multicolumn{3}{c}{ Adjusted R Square } \\
\hline 1 & \multicolumn{3}{c}{0.436} \\
\hline & Hasil uji & koefisien & determinasi
\end{tabular}

(R2) memiliki nilai yang memperlihatkan potensii variabel bebas terkait untuk memberikan penjelasan akan varian variabel tergantung. Tabel 6 menunjukkan "nilai Adjusted $R$ Square sebesar 0.436 atau sebesar $43.6 \%$ dipengaruhi oleh variabel profitabilitas, likuiditas, ukuran perusahaan, leverage, umur perusahaan, dan islamic governance score. Nilai sisa sebesar $56.4 \%$ dipengaruhi variabel lain yang tidak termasuk dalam penelitian ini".

"Hasil uji t pada tabel 5 menunjukkan bahwa variabel profitabilitas dengan sig $0.682>0.05$ tidak memberi pengaruh pada Islamic Social Reporting. Kenaikan atau penurunan profitabilitas perusahaan tidak akan memperluas informasi Islamic Social Reporting (Aini et al., 2017). Tingkat keuntungan atau kerugian yang didapat oleh bank syariah tidak memiliki banyak pengaruh dalam praktik ISR. Pertanggungjawaban sosial sesuai syariat Islam yang diungkapkan BUS menjadi bentuk tanggung jawab akuntabilitas perusahaan pada Allah SWT dan khalayak umum serta mencukupi kepentingan stakeholders lain spesifik stakeholders muslim (Herawati et al., 2019).

Hasil uji t pada tabel 5, diketahui bahwa H2 tidak terdukung. Hal ini mungkin dipengaruhi oleh ketidakpahaman bank syariah dalam menjaga tingkat likuiditas. Seperti yang telah kita bahas sebelumnya bahwa likuiditas merupakan kemampuan perusahaan membayar atau melunasi kewajiban hutangnya. Meskipun bank syariah memiliki likuiditas tinggi tidak menyurutkan perusahaan untuk mengungkapkan ISR karena tidak akan membuat perusahaan bangkrut ataupun hutangnya terlunasi. Justru dengan mengungkapkan likuiditas tinggi dalam pelaporan keuangan atau pengungkapan ISR akan menjadi informasi lengkap bagi kreditur (Yentisna dan Alfin, 2019).

Hasil uji t pada tabel 5, diketahui bahwa H3 tidak terdukung. Ditarik kesimpulan, ukuran perusahaan tidak memberi pengaruh pada Islamic Social Reporting. Islamic Social Reporting pada perbankan syariah bukan hanya didasarkan pada total asset perusahaan, tetapi dapat diketahui dari laporan laba rugi perusahaan. Sebab total asset bukan merupakan satusatunya sumber untuk menilai baik buruk perusahaan pada perbankan syariah dalam Islamic Social Reporting (Lestari, 2016).

"Hasil uji t pada tabel 5, diketahui bahwa H4 terdukung. Ditarik kesimpulan, leverage memberi pengaruh pada Islamic Social Reporting. Entitas dengan leverage tinggi harus memenuhi informasi kreditnya. Semakin tinggi tingkat leverage maka meningkatkan peluang perusahaan untuk mengingkari kontrak kreditnya dan cenderung memperlihatkan labanya karena tinggi (Yentisna \& Alvian, 2019). Pengungkapan informasi tanggung jawab sosial dibutuhkan guna mengurangi kekhawatiran dan memunculkan kepercayaan nasabah maupun investor atas pemenuhan hak-haknya sebagai kreditur.

$$
\text { "Variabel umur perusahaan }
$$
dinyatakan tidak memiliki pengaruh terhadap islamic social reporting dalam penelitian ini. Hipotesis tidak terdukung dengan nilai t sebesar -0.222 dengan nilai sig sebesar 0,826 > 0.05. Hal ini mungkin disebabkan oleh ketidakwajiban bank syariah dalam mengungkapkan sosial kepada masyarakat maupun investor karena tidak adanya standar, aturan, atau UndangUndang yang mengatur hal tersebut".

"Berdasarkan hasil pengujian variabel IGS terhadap pengungkapan islamic social reporting diperoleh hipotesis tidak terdukung dan $\mathrm{t}$ sebesar -0,176 dengan signifikansi 0,503 yang berarti variabel IGS tidak memiliki pengaruh terhadap pengungkapan ISR. Ketika para investor akan berinvestasi pada perusahaan syariah, 
tentu yang utama diperhatikan adalah laporan keuangan. Informasi terkait good corporate governance sedikit diabaikan sehingga perusahaan tidak membuat laporan ISR secara maksimal".

\section{KESIMPULAN DAN SARAN}

Kesimpulan dari penelitian ini adalah hanya satu variabel yaitu leverage yang memberikan dampak lebih pada islamic social reporting. Kelima variabel lainnya diantara lain "variabel profitabilitas, likuiditas, ukuran perusahaan, umur perusahaan, dan islamic governance score tidak memiliki pengaruh terhadap islamic social reporting".

Keterbatasan dalam penelitian ini diantaranya : "1) Penelitian hanya memakai 4 variabel independen yakni profitabilitas, likuiditas, ukuran perusahaan, leverage, umur perusahaan, dan islamic governance score untuk mengetahui variabel yang mempengaruhi Islamic Social Reporting. Penelitian selanjutnya dapat menggunakan variabel lainnya untuk mendapatkan hasil penelitian yang lebih memuaskan seperti ukuran dewan pengawas syariah, tipe industri, kinerja keuangan, dan lainnya; 2) Penelitian hanya memakai sampel 8 bank umum syariah sehingga belum bisa menggambarkan Islamic Social Reporting secara keseluruhan pada Perbankan Syariah di Indonesia. Penelitian selanjutnya dapat menggunakan semua jenis Bank Perkreditan Rakyat Syariah \& bank syariah Unit Usaha Syariah (UUS) atau sektor syariah selain perbankan dengan menggunakan Indonesia Syariah Stock Index dan Daftar Efek Syariah sebagai objek penelitiannya agar mampu memperlihatkan keadaan pasar modal syariah di Indonesia yang sesungguhnya; 3) Periode observasi penelitian ini tergolong singkat, dari tahun 2016 hingga 2019 hanya terdapat periode observasi selama 4 tahun. Penelitian berikutnya bisa memakai periode observasi yang lebih lama untuk menentukan tren perusahaan dalam mengungkapkan ISR; 4) Belum adanya standar mengenai pengungkapan Islami Social Reporting (ISR) di Indonesia sehingga hasil dalam riset ini masih bersifat subjektif dan berbeda dari setiap peneliti karena menggunakan content analysis. Sehingga guna meminimalkan subjektifitas, peneliti berikutnya bisa bertukar pendapat bersama rekan lainnya atau yang sudah melakukan riset Islamic Social Reporting”.

\section{DAFTAR PUSTAKA}

Affandi, H., \& Nursita, M. (2019). Profitabilitas, Likuiditas, Leverage, dan Ukuran Perusahaan: Sebuah Analisis Islamic Social Reporting (ISR) pada Perusahaan yang Terdaftar di JII. Majalah Ilmiah BIJAK, 16(1), 1-11.

Aini, N., Susilowati, Y., Indarti, K., \& Age, R. F. (2017). Pengaruh Umur Perusahaan, Ukuran Perusahaan, Leverage, Likuiditas, Profitabilitas dan Kinerja Lingkungan Hidup Terhadap Pengungkapan Islamic Social Reporting Pada Perusahaan Yang Terdaftar Di Jakarta Islamic Index (JII) Tahun 2012 - 2015. Dinamika Akuntansi, Keuangan, Dan Perbankan, 6(1), 67-82.

Astuti, S. (2019). Analisis Faktor-Faktor Yang Mempengaruhi Pengukuran Pengungkapan Corporate Social Responsibility (CSR) Perbankan Syariah Berdasarkan Indeks Islamic Social Reporting (ISR). Jurnal Akuntansi \& Manajemen Akmenika, 16(1), 162-174.

Aziz, M. R., Roekhudin, \& Andayani, W. (2019). Analisis Efek Ukuran Perusahaan, Profitabilitas, Likuditas, dan Kinerja Lingkungan Terhadap pengungkapan Islamic Social Reporting. Jurnal Ekonomi Modernisasi, 15(2), 67-76. https://doi.org/10.21067/jem.v15i2 .4089

Citravury, D., Mulyati, S., \& Icih. (2019). Analisis Pengaruh Ukuran 
Jurnal Ilmiah Ekonomi dan Bísnís

Vol. 18. No.1,Maret $2021: 65-73$

EISSN : $2442-9813$

ISSN : $1829-9822$

Perusahaan, Jenis Industri, Umur

Perusahaan, dan Penerbitan

Sukuk Terhadap Tingkat

Pengungkapan Islamic Social

Reporting ( ISR ) Pada

Perusahaan Yang Terdaftar di

Daftar Efek Syariah (Des) Tahun

2010-2012. Journal Islamic

Economic, Accounting and

Management, 1(1), 1-25.

https://doi.org/10.35310/tsarwatic a.v1i01.82

Dewi, M. A., \& Putri, C. M. (2018). Analisis Yang Memengaruhi Pengungkapan Islamic Social Reporting. Reviu Akuntansi Dan Bisnis Indonesia, 2(2), 107-115.

Eksandy, A., \& Hakim, M. Z. (2018). Faktor-Faktor Yang Berpengaruh Terhadap Pengungkapan Islamic Social Reporting pada Perbankan Syari'ah Indonesia Periode 20112015. Jurnal Akuntansi Maranatha, 10(2), 187-198. https://doi.org/10.28932/jam.v10i 2.1084

Farook, S. Z., \& Lanis, R. 2003. Banking on Islam? Determinants of CSR Disclosure. International Conference on Islamic Economics and Finance.

Hasanah, N. T., Widiyanti, N. W., \& Sudarno. (2017). Analisis Pengaruh GCG dan Kinerja Keuangan Terhadap Pengungkapan Islamic Social Reporting (ISR). E-Journal Ekonomi Bisnis Dan Akuntansi, 5(2), 115-120.

Herawati, Rawi, \& Destiana, R. (2019). Pengaruh Roa dan Ukuran Dewan Pengawas Syariah Terhadap Islamic Social Reporting Pada Bank Umum Syariah. Jurnal Akuntansi, 14(1), $1-12$.

Hidayah, K., \& Wulandari, W. M. (2017). Determinan Faktor Yang Mempengaruhi Social Reporting
Pada Perusahaan Pertanian Yang Terdaftar Di Indeks Saham Syariah Indonesia (ISSI) Tahun 20122015. Journal of Islamic Economics and Business Volume, 2(2), 213-238. https://doi.org/10.24042/febi.v2i1. 943

Lestari, S. (2016). Pengaruh Tingkat Profiabilias, Likuiditas, Leverage, Ukuran Perusahaan dan Umur Perusahaan Terhadap Pengungkapan Islamic Social Reporting Pada Perbankan Syariah Indonesia Tahun 2010-2014. Jurnal Akuntansi AKUNESA, 4(2), $1-24$.

Maulina, R., \& Iqramuddin. (2019). Pengaruh Likuiditas, Financial Leverage, Profitabilitas Terhadap Pengungkapan Islamic Social Reporting (ISR) dan Dampaknya Terhadap Nilai Perusahaan Pada Bank Umum Syariah Di Indonesia. Jurnal AKBIS, 3(1), 57-72. https://doi.org/10.35308/akbis.v0i0 .1021

Mokoginta, R. M., Karamoy, H., \& Lambey, L. (2018). Pengaruh Komisaris Independen, Dewan Pengawas Syariah, Kepemilikan Institusional, dan Profitabilitas Terhadap Tingkat Pengungkapan Tanggung-jawab Sosial pada Bank Syariah di Indonesia. Jurnal Riset Akuntansi Dan Auditing "Goodwill," 9(1), 55-71. https://doi.org/10.35800/jjs.v9i1.19 103

Nuraeni, A., \& Rini. (2019). Faktor faktor Yang Mempengaruhi Pengungkapan Islamic Social Reporting. JEBI (Jurnal Ekonomi Dan Bisnis Islam), 4(1), 77-83.

Ramadhani, F., Desmiyawati, \& Kurnia, P. (2016). Pengaruh Ukuran Perusahaan, Profitabilitas, Leverage, dan Ukuran Dewan Pengawas Syariah Terhadap 
Pengungkapan Islamic Social Reporting. JOM Fekon, 3(1), 2487-2500.

Sulistyawati, A. I., \& Yuliani, I. (2017).

Pengungkapan Islamic Social

Reporting Pada Indeks Saham Syariah Indonesia. AKUISISI:

Journal of Accounting \&

Finance, 13(2), 15-27. https://doi.org/10.24127/akuisisi. v13i2.166.g124

Sunarsih, U., \& Ferdiyansyah. (2017). Determinants Of The Islamic Social Reporting Disclosure. AlIqtishad: Jurnal Ilmu Ekonomi Syariah, 9(1), 69-80. https://doi.org/10.15408/aiq.v9i1. 3771

Taufik, Widianti, M., \& Rafiqoh. (2015). Pengaruh Islamic Governance Score, Leverage, dan Profitabilitas Terhadap Islamic Social Reporting Index Pada Bank Umum Syariah Di Indonesia. Jurnal Manajemen Dan Bisnis Sriwijaya, 13(2), 177-198.

https://doi.org/10.29259/jmbs.v1 3i2.3348

Wahyuni, S. (2018). Islamic Social Reporting Disclosure and Determinant Factors: Empirical Evidence from Islamic Banks in Indonesia. Advances in Social Science, Education and Humanities Research, 231(Amca), 389-392. https://doi.org/10.2991/amca18.2018.107

Widiyanti, N. W., \& Hasanah, N. T. (2017). Analisis Determinan Pengungkapan Islamic Social Reporting (ISR). Jurnal Bisnis Dan Manajemen Islam, 5(2), 239-264.

Yentisna, \& Alvian, A. (2019). Pengaruh Profitabilitas, Likuiditas, dan Leverage Terhadap Islamic Social Reporting Pada Bank
Umum Syariah Di Indonesia. MENARA Ilmu, 13(10). 